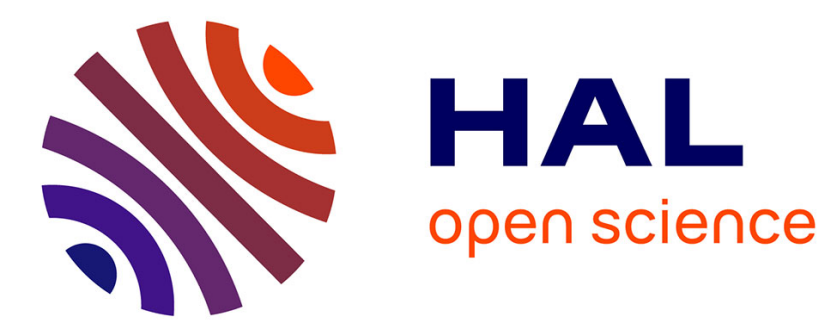

\title{
Are emotions perceptions of value?
}

Jérôme Dokic, Stéphane Lemaire

\section{To cite this version:}

Jérôme Dokic, Stéphane Lemaire. Are emotions perceptions of value?. Canadian Journal of Philosophy, 2013, 43, pp.227-247. 10.1080/00455091.2013.826057 . hal-02972100

HAL Id: hal-02972100

\section{https://hal-univ-rennes1.archives-ouvertes.fr/hal-02972100}

Submitted on 26 Oct 2020

HAL is a multi-disciplinary open access archive for the deposit and dissemination of scientific research documents, whether they are published or not. The documents may come from teaching and research institutions in France or abroad, or from public or private research centers.
L'archive ouverte pluridisciplinaire HAL, est destinée au dépôt et à la diffusion de documents scientifiques de niveau recherche, publiés ou non, émanant des établissements d'enseignement et de recherche français ou étrangers, des laboratoires publics ou privés. 
Are emotions perceptions of value?

Jérôme Dokic and Stéphane Lemaire

IJN-EHESS et Université de Rennes1

\begin{abstract}
A popular idea at present is that emotions are perceptions of values. Most defenders of this idea have interpreted it as the perceptual thesis that emotions present (rather than merely represent) evaluative states of affairs in the way sensory experiences present us with sensible aspects of the world. We argue against the perceptual thesis. We show that the phenomenology of emotions is compatible with the fact that the evaluative aspect of apparent emotional contents has been incorporated from outside. We then deal with the only two views that can make sense of the perceptual thesis. On the response-dependence view, emotional experiences present evaluative responsedependent properties (being fearsome, being disgusting, etc.) in the way visual experiences present response-dependent properties such as colors. On the responseindependence view, emotional experiences present evaluative response-independent properties (being dangerous, being indigestible, etc.), conceived as 'Gestalten' independent of emotional feelings themselves. We show that neither view can make plausible the idea that emotions present values as such, i.e., in an open and transparent way. If emotions have apparent evaluative contents, this is in fact due to evaluative enrichments of the non-evaluative presentational contents of emotions.
\end{abstract}




\section{Introduction: the direct access thesis}

A popular view at present is that emotions are perceptions of values. At first sight, such a broad view is difficult to assess because there are numerous potential similarities and dissimilarities between emotions and perception. The nature of perception and perceptual experiences is itself a moot question, so which similarities and dissimilarities there are to uncover will also depend on one's theoretical stance in this domain. ${ }^{1}$ Here, we are going to focus on one specific element of the perceptual analogy, which concerns the content of the emotions, or what the emotions are intentionally about. The issue we are interested in is whether emotions can be understood as perceptions whose contents are evaluative. With regard to this specific issue, most authors have defended what we are going to call the direct access thesis. According to this thesis emotions give us direct access to evaluative properties, in the sense that they perceptually present these properties at the level of their contents. Just as sensory perception is a form of 'openness' to the sensible world (McDowell 1996), emotions should be conceived as instances of openness to values. For instance, our emotional experience of fear involves the perceptual presentation of the fact that this dog is dangerous or fearful. D'Arms and Jacobson write, with the declared intention of reflecting a widely shared opinion: 'Most recent accounts of the structure of emotion, despite their differences, agree that emotions (somehow) present the world to us as having certain value-laden features. Following their lead, we will say that emotions involve evaluative presentations' (2000a, 66). Similarly, Tappolet summarizes her view by saying that '[I]n Meinong's terminology, emotions would present values or at least some of them' $(2000,173)$. Another illustration is Goldie, who claims that '[w]hen we respond emotionally to things in the environment, we also, as part of the same experience, typically perceive those things as having the emotion-proper property' $(2004,97)$, where the emotion-proper properties (frightening, disgusting, shameful, etc.) are the evaluative properties proper to each emotion type. ${ }^{2}$

\footnotetext{
${ }^{1}$ For a thorough discussion of potential similarities and dissimilarities, see Salmela (2011). 2 This view is also clearly held by Deonna (2006), De Sousa (2002), Döring (2007) and Tye (2008). Wiggins (1987) and McDowell (1985) come close to this view but Wiggins does not state it explicitly and McDowell insists that the idea should only be taken metaphorically. Johnston (2001) suggests that affectivity involves the presentation of values but curiously and, we may suppose, intentionally, he does not apply this suggestion to emotions. Mulligan
} 
In what follows, we argue against the direct access thesis, and suggest that itmay be more misleading than beneficial for a proper understanding of the nature of emotions. ${ }^{3}$ Although we are not going to discuss the epistemological implications of the direct access thesis, our criticism should also be relevant to understanding the rationality of the transition from emotions to evaluative judgments. If emotions are not perceptual presentations of values, they cannot justify or warrant evaluative judgments in the way, for instance, the visual perception of a red balloon can justify or warrant the judgment that there is a red balloon. Our discussion is structured as follows. In the next section, we introduce the notion of direct access with respect to perception in general. As we understand it, this notion points to a distinction between what is perceptually presented and what is only represented in our experience. The significance of the distinction is that our nai"ve notion of perceptual content typically incorporates states of affairs which we do not have access to but which co-vary with our experience in interesting ways. Such incorporation is often implicit, so we are naturally inclined to self-ascribe perceptual contents that are richer than what is perceptually presented to us. In arguing against the direct access thesis, we are going to use that distinction to suggest that the apparent evaluative content of emotion is in fact the product of an informational enrichment initiated outside emotion. Our emotional experiences themselves do not present values as such, i.e., in an open and transparent way. Thus, the distinction between perceptual presentation and representation enables us to identify what we see as the main challenge faced by proponents of the view that emotions are perceptions of values; namely, to show that the apparently evaluative content of emotions has not been enriched from outside, through habits, past experience, general beliefs or mere associations. Otherwise, their view would entail that emotions do not perceptually present values as such after all, or that they are not an original source of experience of evaluative states of affairs.

In our view, there are only two general ways of fleshing out the direct access thesis. In Section 3, we turn to the first of these ways, which we call the response-dependence

(1998) defends the view that emotions justify evaluative beliefs, but he does not go as far as claiming that emotions are perceptions of values.

${ }^{3}$ Whiting (2012) also argues against (what we call here) the direct access thesis. Although most of our objections are rather different, it is interesting to notice that, on certain specific points, our own objections may be seen as furthering or complementing his criticism from a different angle. 
view. This view exploits an analogy between emotions and perceptions of colors, and relies on the claim that emotions are perceptions of response-dependent evaluative properties, such as being fearsome or disgusting. Response-dependent properties are properties whose instantiation constitutively depends on the availability of some cognitive response, such as a perceptual or an affective experience. However, we shall argue that the response-dependence view eventually prevents the proponents of the direct access thesis from explaining the properly evaluative character of the response-dependent properties that are supposed to be perceptually presented through emotions. Section 4 is about the second way of understanding the direct access thesis, which we call the responseindependence view. This view construes the evaluative content of the emotion as a further Gestalt pertaining to the object of the emotion. As this Gestalt is supposed to be presented independently of the feelings that are part of the emotional experience, it can be conceived as response-independent, like the property of being dangerous or indigestible. As we show, though, the connection between emotions and response-independent values is far from being transparent to the nar"ve subject, and often can be made only quite indirectly. Emotions themselves do not perceptually present response-independent values at all; the subject can be aware of those only through other, independent mental states.

In a nutshell, the direct access thesis cannot be maintained, and we are left at best with the claim that emotions are perceptual representations of values, as the result of incorporating into emotional content evaluative material coming from outside the sphere of our emotional experience.

\section{The direct access thesis: preliminary distinctions}

\subsection{Direct vs reliability-based access}

As mentioned above, our target in this paper is the direct access thesis, according to which emotions are, or involve, perceptual experiences that present values to us, i.e., that reveal them to us openly and transparently. In short, emotions give us direct access to values as such. Some philosophers might reject the direct access thesis and nevertheless insist that emotions are perceptions of values, i.e., that the latter can figure in the contents of emotional experiences. This is a coherent option only if we can perceive more than what we have direct access to in our perceptual experience.

Consider Prinz's neo-Jamesian view. On this view, emotions are direct perceptions of 
characteristic bodily changes (Prinz 2004; see also 2007). However, Prinz also suggests that emotions are reliable indicators of what he calls 'concerns', namely specific organism-environment relations that bear on well-being, such as dangers, losses or offenses. ${ }^{4}$ Concerns are value-laden, but they are ontologically independent of the emotions they cause in us. Here, Prinz avails himself of Dretske's consumerist semantics according to which, roughly, reliable internal indicators of $\mathrm{X}$ can become genuine representations of $\mathrm{X}$, to be used in practical and theoretical reasoning. In particular, emotions can become genuine representations of concerns within the relevant cognitive system.

Initially, Prinz (2004 see 60 and 68) has been careful not to claim that emotions are perceptual experiences of concerns, even if the former represent the latter. What we perceive through emotions are only value-free bodily changes. This is consistent with the general claim that what we perceive is exhausted by what we have direct access to in our perceptual experience.

Later on, though, Prinz (2006a, see 146 and 158) argues that the way emotions represent concerns makes them genuine perceptions of concerns. ${ }^{5}$ Prinz's later theory makes sense in the context of a reliabilist conception of perception. On this conception, we can perceive states of affairs that are not openly and transparently given to us, under two main conditions: first, our experiences co-vary reliably with these states, and second, such co-variation can be exploited by our cognitive system, which thus should be able to represent the relevant states independently of our experiences. ${ }^{6}$ In the case in point, emotions would be directly only about mere bodily changes, but their contents could reach

\footnotetext{
${ }^{4}$ In his book (2004), Prinz uses the expression 'core relational themes', which he borrows from Lazarus, as the generic expression referring to non-response-dependent evaluative properties such as danger, loss, etc. However, 'core relational themes' is replaced by 'concerns' in his (2006a) paper. For simplicity, we stick with the second expression in our discussion.

${ }^{5}$ Furthermore, he no longer insists that emotions are perceptions of patterned changes in the body, but says that the former merely 'register' the latter.

${ }^{6}$ In fact, he endorses in his (2006b) a very liberal form of reliabilism about perception. For instance, he allows for the visual perception of raised hands to represent the property of being a philosophy major, in a context in which you have told your students to raise their hands if they are philosophy majors.
} 
to, i.e., represent, concerns, even though the latter are not given openly and transparently to us in our emotional experience. Thus, emotions represent values only because the latter can be independently represented and at least implicitly understood as what the former co-vary with.

\subsection{What is seen: presented content and beyond}

The reliabilist conception of perception trades on the distinction between perceptually presenting and representing the world. ${ }^{7}$ In order to get a better grip on this distinction, let us examine two intuitive descriptions of perceptual situations outside the sphere of emotions:

The dispute.

Pierre visits his friends Marie and Jacques and sees that they have just had an issue, by seeing pieces of broken plates scattered all around the kitchen floor.

The hot plate.

Pierre sees that the cooking plate is hot, by seeing that it is reddening.

In both cases, one can argue that what Pierre has perceived goes beyond what is properly presented in his perceptual experiences. Pierre is visually presented with broken plates on the kitchen floor, but not with the dispute itself. He is visually presented with the color of the cooking plate, but not its temperature (which is not a proper object of vision). Now the recent dispute and the temperature of the cooking plate are states of affairs that are (more or less) reliably connected to Pierre's perceptual experiences. Moreover, a cognitive system can recruit these experiences as representations of these states since it is part of Pierre's background knowledge of the world that broken plates (red cooking plates) often indicate an issue (hot cooking plates). To this extent, Pierre's visual experiences represent the dispute and a hot cooking plate.

Of course, the distinction between what is presented and what is merely represented in our perceptual experience is hostage to a substantial theory of perception, which we cannot provide here. Our remarks about these examples are offered simply as possible (and hopefully plausible) illustrations of this distinction. The important point to notice at this stage is that we are usually immediately aware of what our perceptual experiences

\footnotetext{
${ }^{7}$ In using this terminology, we do not mean that perceptual presentations are not also perceptual representations. The important point is that what is perceptually represented need not be perceptually presented.
} 
represent, even when the latter is not perceptually presented. This is why we are prone to make rather generous self-ascriptions of experiences. Indeed, Pierre might spontaneously report having seen that Marie and Jacques had just had an issue and that the cooking plate was hot. We tend to conceive of 'what we perceive' in a broad way, encompassing contents that we are immediately aware of even though we do not experience them openly and transparently.

\subsection{Informational enrichment}

What the foregoing discussion shows is that it is of crucial importance to distinguish between what is perceptually presented and what may appear as perceptually presented but is in reality only represented. Let us say that the presented content of an experience is the state of affairs that the experience itself discloses to the subject independently of further cognitive processing (such as judgments or inclinations to judge on the basis of the experience). However, as a result of this further cognitive processing that may include informational enrichment, the experience can appear to present further states of affairs although it only represents them. For instance, Pierre's past acquaintance with his friends' manners, as well as repeated experiences of the correlation between the redness and the hotness of cooking plates have enabled apparent perceptual contents that are richer than what is presented in his current perceptual experience. ${ }^{8}$

When a philosopher says that emotions are perceptions of values, it is crucial to ascertain whether she means that values are presented or merely represented in our emotional experiences. The problem is that such a philosopher often relies on our naïve theory of perception which, as we saw, does not really distinguish between perceptual presentation and representation made conscious through enrichment. The really interesting locus of debate resolves around the direct access thesis, i.e., whether emotions involve perceptual presentations of values. For if values are merely represented in our emotional experiences, the apparent evaluative contents of the latter must have been enriched from outside. That is, if emotions themselves cannot be seen as cases of openness

\footnotetext{
${ }^{8}$ Again, these examples are offered only as possible illustrations of the conceptual distinction between presentational and representational contents. What is actually perceptually presented in our sensory experiences is at least partly an empirical matter.
} 
to values, the fact that they represent values must be explained by reference to nonemotional states.

In other words, the neglect of the distinction between perceptual presentation and representation can lead to a trivialization of the claim that values are perceivable. Consider another intuitive description of a perceptual situation:

The Stop sign.

While driving, Pierre sees that he ought to stop his car before proceeding, by seeing the Stop sign in front of him.

This description entails that what Pierre sees is a normative state of affairs (that I ought to stop my car). But this content obviously goes beyond what is visually presented to him, namely a particular traffic sign. Since Pierre is an experienced driver, he does not need to infer the judgment that he ought to stop his car from independent premises. Rather, he is immediately aware of the relevant normative state of affairs. Although Pierre's visual experience represents this state of affairs, it is obvious that he has no direct perceptual access to it. Otherwise, it would be too easy a way to prove that we can perceive norms or values. Even if the representational content of the driver's perceptual experience involves a normative state of affairs, it is clearly the product of some form of external informational enrichment. The normative material does not come from the experience itself, but has been brought in by background beliefs or cognitive habits.

In what follows, we shall discuss the only two ways in which the direct access thesis may be fleshed out. Indeed, the value properties presented in the emotional content may be either response-dependent or response-independent. On the first option, the presentation of evaluative properties is often described by analogy with the perception of colors when colors are themselves conceived as response-dependent properties. Since the experience as of something red ordinarily is the perception of a red object, it is suggested that the experience of fear in the presence of a barking dog ordinarily is a perception of the barking dog as fearsome. On this option, the evaluative content of the emotion (fearsome) is presented under the guise of the emotional experience itself (fear). By contrast, the second option claims that the emotional presentation of values must be understood as the perception of response-independent properties. The distinctive point of this second option is that, when an object is seen as presenting a certain response-independent property, the ontology of the property presented in perception does not depend essentially on the experience of this very property. Transposed to the case of emotions, the idea would be that the evaluative properties presented in emotions are essentially independent from the 
experiential, feeling-like dimension of emotions. For instance, it would be part of an experience of fear that its object is seen as dangerous although this further way in which the object of the emotion is presented does not rely at all on the feelings inherent in our experience of fear.

\section{The response-dependence view}

Let us start with the response-dependence view. The first step toward such a view is to notice after Wiggins that there are pairs of emotions and values that strike us as being 'made for one another' $(1987,199)$. This is true of fear and fearsome, disgust and disgusting, amusement and amusing, admiration and admirable, among others. Building on this undisputable fact, it is natural to suggest that in certain circumstances, being an object of admiration contributes to the object being admirable and thus that they are secondary properties. ${ }^{9}$ The next step is then to follow McDowell, who famously suggested that if values are secondary qualities, then it is possible to perceive these qualities themselves. This is possible because '[s]econdary-quality experience presents itself as perceptual awareness of properties genuinely possessed by the objects that confront one' (1985, reprinted in 1998, 134). The final step, in line with some suggestions of McDowell himself, is to apply this account of the perception of value to emotions. Indeed, the pairs of emotions and values that we listed above make it tempting to hypothesize that when we are afraid of a given object, the experience of fear presents the object as being fearsome, that when we are amused, the experience of amusement presents its object as being amusing, etc. In other words, if the experience of red that we have when seeing an object is a perception of an object as being red, why not say that an experience of fear in front of an object is a perception of this object as being fearsome? Similarly, an emotion of disgust toward a corpse in decay would be a perception of the disgustingness of the corpse in decay, etc. In each case, the emotional experience would count as a perception unless it is defeated. This is the view that D'Arms and Jacobson have argued for, in so far as they qualify their sentimentalist theory as a form of perceptivism which is understood on the model of the perception of colors themselves conceived as secondary properties $(2005,190) .{ }^{10}$ In what follows,

\footnotetext{
${ }^{9}$ Although Wiggins himself does not make this suggestion.

${ }^{10}$ Although they have insisted that 'talk of the perception of value should be taken
} 
we shall refer to the color model as the model that explains how emotions are perceptions of response-dependent evaluative properties by relying on the perception of colors. Nevertheless, it is worth noting that, if one wants to earn the right to rely on the color model in order to explain how emotions present response-dependent values, two points need to be secured. First, emotional experiences must present values just as visual experiences of red present redness. In other words, the evaluative intentional content of emotions must be presented through our emotional feelings, under the guise of the emotional experience. Second, the value properties that are presented in emotions must be response-dependent. In fact, D'Arms and Jacobson are keen on saying that since 'greenness is essentially a matter of how things appear visually', 'the same goes for value' $(2005,189)$. Therefore, the evaluative properties that are presented 'are inevitably response-dependent', which means that emotions 'purport to be perceptions of such properties as the funny, the shameful, the fearsome, the pitiable, etc.' $(2000 a, 66)$. Insofar as Tappolet (2011) is perfectly clear that the presented content of emotions is non-conceptual but conceptualized with response-dependent concepts, she may be understood as adopting the color model. ${ }^{11}$ As we will argue, the major difficulty for the defender of the response-dependent view is to secure both these points.

\subsection{The gap between dispositions and values}

The problem that we want to raise now is that relying on the color model in fact undermines the very idea that emotions present values. Indeed, the color model eventually implies that emotions do not present values. To see this, let us take a closer

metaphorically' $(2005,187)$ or that the 'analogy' is 'imperfect' $(2000 \mathrm{a}, 67)$, it is important to notice that these ways of downplaying the idea that emotions are perceptions of value do not concern the crucial point on which our paper focuses. Essentially, the point of these restrictions is to emphasize the 'persistence of disagreement' (2005), the 'lack of dedicated emotional organs', and the fact that 'one need not be in the presence of the object of one's occurrent emotions' (2000a, 67). Considered as such these points are objections to a complete analogy between emotions and ordinary perceptions. However, these disanalogies do not bear on the more specific thesis that emotions present values like visual experiences present colors.

11 See our Section 4.1 . 
look at the case of redness. Although the experience of redness is a subjective response, we are allowed to say that we perceive the objective redness of objects because redness is a dispositional property. In other words, it is because redness is defined as the property we experience as red in normal conditions that we are allowed to say precisely that we perceive an object as being red in normal conditions. Now, the color model implies that an experience of fear in front of an object in normal conditions allows us to say that we perceive the object as fearsome. However, if we follow the color model faithfully, we must conclude that the property fearsome that is in play here is the dispositional property of being fearsome, as our experience of red allows us to attribute the dispositional property of being red. In other words, the color model allows us to say that fear in normal conditions presents us with objects that trigger or have the disposition to trigger fear, but nothing beyond that. Therefore, this model leads directly to the conclusion that emotions are perceptions of dispositional properties such as fearsome, disgusting, amusing, etc. We have not earned the right to conclude anything stronger and especially not that emotions are perceptions of the value properties that bear the same name but that are plainly different. ${ }^{12}$

In relying on the color model, one is therefore led to the following difficulty: one has to explain how emotions can present genuinely evaluative and not merely dispositional properties. Insofar as the definition of red as a mere dispositional property does not seem to leave room for any evaluative aspect of this property, the same should go for the definition of fearsome and disgusting as mere dispositional properties. In a nutshell, the claim that the properties presented in emotions are evaluative rather than merely dispositional cannot be motivated by the color model alone.

In fairness to friends of the color model, it is worth emphasizing that our complaint is not that they have overlooked the fact that evaluative perceptions differ from color

\footnotetext{
${ }^{12}$ In fact, it is still possible for the defender of the response-dependence view to insist that the value property fearsome is nothing other than the dispositional property of triggering fear in normal conditions. Indeed, this dispositional view definitely implies that we have a direct access to value properties as we have direct access to colors. Nevertheless, the dispositional view is now widely considered as mistaken (e.g., McDowell 1985; Wiggins 1987; D’Arms and Jacobson 2005; Tappolet 2000), precisely because it does not account for the normativity of a
}

value property such as fearsome, which merits fear, or makes fear correct. 
perceptions.13 It is rather that they do not tell us how two types of experiences that are considered, and indeed seem, analogous - experiences of red and experiences of fear present two different types of content: a non-evaluative property in the case of redness and an evaluative property in the case of fearsome.

\subsection{Is the gap bridgeable?}

The friends of the color model may suggest that we have not paid enough attention to our emotional experiences and that once we do so, it becomes obvious that our emotions present an evaluative content through the model's experiential aspects. After all, it seems quite intuitive to say that at least sometimes we are directly aware, through our experience of disgust, that an object is disgusting in the evaluative sense. Yet, it is fair to say that the defenders of the color model are not very prolix when it comes to explaining in detail how emotions involve an 'evaluative presentation' or 'present value-laden features'.14 In what follows, we present the only two options that seem available to them and we try to show that neither of them is very promising.

On a first option, it might be suggested that the emotional experience itself presents an evaluative property under the guise of this very emotional experience or an aspect thereof. Thus, for instance, fear would have an evaluative aspect. But what could it be? The beating of our hearts and our sweating are no more evaluative than our visual experience of red, and presumably this is true of all our bodily feelings. Bodily feelings are nothing but experiences of bodily states. Moreover, we may wonder how even the sum or a combination of bodily states can have an evaluative aspect. Notice that our argument does not need to rest on a restricted view of the emotional experience. We can acknowledge, and it is quite plausible, that when we experience an emotion we are also aware of motivations or changes in the focus or width of our attention. Nevertheless, being aware of such motivations or changes in our attention does not involve an evaluation of the object of the emotion.

In his own attempt to explain the direct access thesis, Goldie claims that an emotion involves a 'feeling towards' that is a mental feeling directed toward the object of the emotion. In addition, he claims that "when we respond emotionally to things in the environment, we also, as part of the same experience, typically perceive those things as having the emotion-proper property.' $(2004,97)$. These emotion-proper properties are the response-dependent evaluative properties listed above: fearsome, disgusting, shameful 
and the like. Thus, putting these claims together, his view is that feelings toward are not only directed toward the object of our emotions but present the response-dependent evaluative property specific to each emotion.

With regard to our specific concern here, one might wonder how mental 'feelings toward' can present evaluative properties. Goldie proposes that 'for each sort of emotion, there will be a broadly characteristic qualitative nature of these feelings' $(2000,19)$. It is hard to understand, though, how these qualitative feelings could present something evaluative. In general, we have no idea of qualitative experiences presenting evaluative properties. Experiences of colors, sounds, headaches, even possible mental experiences such as the experience of the fluency of a mental process, etc., are evaluatively neutral.

Therefore, the notion of an evaluative feeling might well be an oxymoron. At this point, one might want to resist this conclusion by pointing to the fact that most emotions, if not all, are themselves pleasant or unpleasant. Could we not suggest that our emotional experiences in being pleasant or unpleasant present their object as being good or bad in some way or other?15 Perhaps the unpleasantness of shame presents the responsedependent property shameful and this presentation is evaluative since shame is itself unpleasant and thus is able to present the object of shame as having a negative value. Indeed, it seems that, in some sense, the object of our emotion is unpleasant in a way characteristic of the experience of shame. However, this is still insufficient for the object of the emotion to be presented as having value. For sure, we may say that the object of our shame is presented as being unpleasant, but this will again be what we may call a dispositional sense of 'unpleasant'. What we will be saying is that in normal conditions this object is experienced as somehow unpleasant. It does not follow that this unpleasant experience is the correct or appropriate experience to have. And this is very bad news for the color model since it shows that even if the emotional experience is itself intrinsically valuable and somehow presents the object as having this value, it appears in reality that the intrinsically valuable aspect of an emotion at best presents its object as having a merely dispositional property.

A second option that could attract the friend of the color model would be to claim that our emotional experience presents itself as an appropriate response to its object.16 In other words, emotions would present the property of appropriateness. For instance, an experience of fear in the presence of a barking dog would present itself as appropriate or required. But then, if for the sake of the argument we identify evaluative properties such as being fearsome with the (possibly) deontic one being such that fear is appropriate, as 
proponents of the Fitting Attitude Analysis of value have suggested, then it would be possible to argue that emotions present values.17 Indeed, given the identification just proposed, if an emotion of fear presents itself as being appropriate, then this fear is thereby presenting the property fearsome.

Unfortunately, this second option does not fare better because it rests on a wildly implausible description of our emotions. It is hard to believe that our emotions reflexively present themselves as being appropriate. Rather, our common experience seems to be that the content of an emotion does not refer to the emotion itself, let alone its appropriateness. Once again, if we follow the analogy with color, the appropriateness of seeing something as red is not part of the perceptual experience of red objects. Similarly, it is no part of the content of an emotion that this same emotion is appropriate.

Our assessment of the two options available within the color model allows us to see why the proposal put forward by Deonna (2006) is also defective. His specific suggestion is that emotions present their objects as 'calling for a certain behavior' or 'as calls for action' $(2006,34)$. Thus, for instance, 'the fear experienced when facing a lion is representing the lion as calling for one's flight (or one's freezing or one's singing a tune, etc.)' $(2006,34)$. This is a version of the color model because Deonna claims that the object of an emotion calling for an action is presented in the bodily experience that is part of the emotion: 'The phenomenology of the body characteristic of the emotional experience is what presents the axiological properties of the environment' (Deonna and Teroni 2008, 80).

In our view, this proposal trades on an ambiguity with regard to the notion of 'calling'. On the one hand, if the call is understood non-normatively as a motivation or as a bodily preparedness toward action, then the proposal is extremely plausible but it fails to explain in what sense emotions present an evaluative or deontic property. Thus, it is subject to the objection raised against the first option available to defenders of the color model. On the other hand, if the call is understood normatively as expressing that a motivation is somehow appropriate or required, then it falls prey to the objections raised two paragraphs above against the second option. Therefore, the proposal fails either way to explain how emotions could present values. 18

\subsection{Enriched contents}

The reader who has followed us so far might still wonder at this point: But why is it so 
tempting to think that emotions present response-dependent values? Our response is that although emotions have no response-dependent evaluative presented content, they appear to have one because their non-evaluative presented content has been evaluatively enriched. Moreover, this enrichment need not be acknowledged by the subject herself. It may in some cases derive from the implicit belief that the object of the emotion makes this emotion appropriate. Therefore, we not only experience the object as triggering our emotion, but also that our emotional response is appropriate, and this is nothing else than to immediately represent the object as having the corresponding response-dependent evaluative property. In some cases, this belief will refer to response-independent properties. For instance, in the case of fear, whether the situation is really dangerous from the subject's point of view will be relevant to the appropriateness of the subject's emotion. The content of the emotion is non-evaluative, yet, since the object is perceived as dangerous independently of the emotion, we experience our emotion as an appropriate fear, and therefore experience its object as being fearsome. Somehow, what we take to be the intentional content of the emotion of fear is its truly non-evaluative content plus the conceptual categorization of this object as being dangerous, a categorization that does not itself rely on the emotion but only on our recognitional capacities with regard to the objects of our visual perception.

In other cases, objective criteria of appropriateness are much less obvious. For instance, the appropriateness of amusement may not rely only on purely responseindependent properties of the object of amusement. But this does not mean that we do not consider either implicitly or explicitly that our laughter is appropriate only in response to certain objects. For example, one may despise uneducated jokes or racist jokes and value other kinds of joke. Alternatively, one may believe that the jokes that are really funny are the less educated, or the more primitive, whatever those might be. Even if one has no view at all on the topic, one is certainly naturally disposed to consider whether one's emotions are appropriate. Therefore, one's laughter may come with the impression that it is appropriate or not. And this, in other words, explains why we experience the object of one's laughter as value-laden. However, this apparent evaluative content is only an enrichment of the emotional content supported by considerations that are extraneous to the emotion itself. In short, in denying that emotions have response-dependent evaluative content, we are not left unable to explain how our emotions can appear to have such evaluative content.

We therefore have to conclude that the perception of color, at least as a response- 
dependent property, is unable to provide a plausible framework to understand how emotions give us a direct access to values. Since our emotional experience does not seem to present response-dependent values, the direct access view has to be defended on other grounds. We need to ask ourselves whether emotions may somehow present responseindependent values.

\section{The response-independence view}

On the response-independence view, emotions give us direct perceptual access to response-independent values. The properties that are perceived in fear, sadness, disgust or amusement are danger, loss, indigestible, incongruous. These properties are responseindependent because, as Prinz (2004, 63-64) has rightly insisted, their very existence does not rest on our dispositions to experience fear, sadness, disgust or amusement. Something is dangerous if and only if it threatens someone's bodily integrity or welfare. Similarly, even if the possibility of a loss requires that someone care about something, the ability to experience sadness is not required for there to be losses. Admittedly, danger and loss are relational properties as far as something may be a danger for one individual but not for another, or for one species and not for another. However, this has no implication for the fact that the very existence of these values does not rest on our responses.

Now, how could emotions present us their object as having response-independent properties? For this to be possible, the response-independent property must be ontologically independent from the experiential aspects of emotion. In other words, these response-independent values must present themselves just as if they were independent of emotional experience; they must present themselves as primary qualities like shape or size.19 If this is correct, then the most plausible model for such a presentation of response-independent values would be that emotions present us their object as having a value property as a further Gestalt or construal imposed on their object. Although Roberts (2003) does not claim that emotions are perceptions of response-independent values in the direct access sense, 20 one may at least build such an account from his suggestion that each type of emotion construes its object as having a specific response-independent value.

Indeed, he further explains the notion of 'construal' as follows:

a construal is not an interpretation laid over a neutrally perceived object, but a characterization of the object, a way the object presents itself. When one see a duck-rabbit as a duck, the figure itself takes on a ducky look. $(2003,80)$ 
Thus, relying on what we may call the Gestalt model, the proposal would be that emotions are perceptions of values because the object of an emotion is always further seen or construed as having an evaluative property. Do“ring may be seen as defending this view insofar as she writes: 'In fearing a snake that you suddenly encounter on a woodland path it seems to you that the snake is dangerous' $(2007,378) .21$ Although Tye's account is more complex, he is committed to the response-independence view. Moreover, he seems to accept the Gestalt model insofar as the bodily response that is part of an emotion does not present the evaluative property that is attributed to the object of the emotion but is a distinct part of what the emotion represents:emotional experiences are experiences directed upon items that are typically external to the body and that represent those items 1) as having an evaluative feature (for example, as being threatening or dangerous) and 2) as causing (or, in some cases, as merely being accompanied by), a certain broadly distribute, internal bodily disturbance $(2008,35)$.

\subsection{Appraisal theories and the non-transparency objection}

Before raising our objections to the response-independence view, we want to emphasize that it is not our aim to deny that emotions may involve or result from an appraisal of our environment.22 In fact, the case in favor of appraisal theories of emotions is quite powerful and we do not want our objection to rely on the rejection of these theories.23 The objection that we want to raise has a different starting point. Recall that the fate of the Gestalt model rests on two theses. First, it must be shown that emotions always involve an evaluative construal of their object in terms of response-independent values. Second, one must make sure that these construals are really part of our emotions themselves. With regard to the first point, it is important to emphasize that, if emotions encompass cognitive appraisals, it does not immediately follow that these appraisals are available under the guise of an evaluative construal of their objects to those who experience these emotions. We must distinguish between the fact that emotions involve an appraisal of their objects and the awareness that the individuals experiencing these emotions may have of this appraisal. The cognitive appraisal underlying emotions may not be transparent to the subject.

Let us then turn to the question of whether emotions present response-independent evaluative properties. To assess this point we may wonder whether the layperson is able to specify the response-independent evaluative properties characteristic of each emotion and of which she is supposed to be aware. If she is unable to do it, then it will certainly be a 
strong clue that in reality no such evaluative properties are presented through our emotions. Within this context, the example that is systematically put forward is fear and, indeed, fear seems to present its object as dangerous. But let us consider other emotions. What about amusement? Is the layman able to tell which evaluative property is presented in our laughter? The sensible response is certainly negative. An often-cited candidate for being the general feature that triggers our laughter is incongruity, but it is doubtful that our laughter presents its object as being incongruous. Moreover, as it has often been argued, there are numerous forms of incongruity and it is clear that not every incongruence is amusing. But we are unable to tell what sort of incongruity is relevant except by saying that it is the kind of incongruity that amuses us. The same goes for the value supposedly presented by disgust. The idea that disgust is an appropriate response to things that may be indigestible or somehow dangerous for our health is also the result of empirical knowledge. It is certainly not a value that is presented in our experience of disgust itself. Therefore, the mere fact that the evaluative features that are supposed to be presented in our emotional experiences are not obvious to us is the best evidence that we are not aware of any evaluation of the objects of our environment through our emotions.

In addition, both philosophers and psychologists disagree about the responseindependent values that are correlated to each type of emotion. The wide disagreement among appraisal theorists about the proper pattern of appraisal specific to each emotion is in and of itself evidence that there are no response-independent evaluative properties that we all 'see' as belonging to the objects of our emotions. It explains why the identification of the pattern of appraisal that corresponds to each emotion is an empirical program.

A final piece of evidence is that the evaluative concepts that figure in emotion-based judgments are much more frequently concepts of response-dependent values. The only indisputable example of a response-independent concept is danger. In comparison, the class of response-dependent concepts that are involved in emotion-based evaluative judgments is much larger. In this second class, we have at least disgusting, frightening, amusing, shameful, embarrassing, despicable, sad and admirable. Why is this so? Once again, we believe that the best explanation is that we use response-dependent evaluative concepts much more frequently precisely because the content of our emotions does not present response-independent evaluative properties. If they were presenting such properties, we would presumably use concepts that refer to the response-independent values.

All these objections against the response-independent view and the Gestalt model 
might still be avoided if the experiential aspects of emotions were presenting responseindependent values, for our use of response-dependent concepts would not come as an objection. In Section 3 above, we discussed and rejected the color model, according to which emotions are presentations of response-dependent evaluative properties just as visual experiences are presentations of response-dependent color properties. Now some philosophers have conceived color as a response-independent property.24 Can this alternative view of color be used as an analogy to support the claim that emotions are presentations of response-independent evaluative properties? We doubt it. Suppose that the response-independent property with which color is identified is a reflectance property of the surfaces of the material things. To begin with, it is not clear that reflectance properties (or for that matter any microphysical properties) are really presented through our chromatic experiences, rather than merely represented. It is certainly not transparent to the naive subject that the redness of the table that she sees is a specific reflectance property. This version of the new analogy is thus of no help to the friends of the direct access view. Just as the nai"ve subject needs some additional information to the effect that her chromatic experiences track reflectance properties, emotions can become perceptions of values only through some kind of informational enrichment of the non-evaluative states of affairs that they present to the subject.

A more sophisticated suggestion is that we can perceive response-independent properties in a response-dependent way, i.e., via some response-dependent mode of presentation (whether conceptual or not). Indeed, some philosophers have drawn a distinction between response-dependence or response-independence as applied to properties, and response-dependence or response-independence as applied to concepts (or to non-conceptual modes of presentation) (Pettit 1991). For instance, a visual experience of the redness of the table would be the perception of a specific reflectance property, which is response-independent, via some response-dependent mode of presentation. Analogously, emotions would be perceptions of response-independent values via response-dependent affective modes of presentation. In our view, though, the claim that a response-independent property is perceived in a response-dependent way can only mean one of two things. On the one hand, one assumes that the relevant responseindependent property (reflectance properties, danger) is presented in a responseindependent way, in order for it to be additionally presented as causing a specific response (a red experience, fear). It is only on this assumption that one can motivate the view that a response-independent property is perceptually presented to the subject. On the other hand, 
one acknowledges that only response-dependent properties are perceptually presented, but that the relevant response-independent properties are merely perceptually represented. In the case of emotion, the former option has been discarded in this section, whereas the second option boils down to the original color model, as discussed and rejected in the previous section.

\subsection{Evaluative enrichment again}

Even if one is convinced by the above argumentation, one may still wonder why it seems to us that disgust presents its object as being indigestible or at least that fear presents its object as being dangerous? Well, in the case of disgust the need for some informational enrichment is fairly obvious. Are we aware of our appraising the oysters that are now provoking our disgust as 'an indigestible object or idea' (Lazarus 1991, 122) because this is how the oysters are perceived when they disgust us? This is not very plausible, especially because not every disgusting object is indigestible. In what sense can a moral wrong be indigestible? A more plausible explanation of our 'perceiving' these oysters as indigestible is instead that we have two reactions when confronted with oysters. On one hand, we are disgusted by the oysters, but on the other hand their presence, our disgust, or both remind us that they might make us sick, as we were last week. Thus, even if we are having an experience of disgust that makes us immediately aware of their being indigestible, the evaluation of the oysters is not part of the emotion itself because it is not presented through our emotional experience. Rather, the value that is represented is an immediate consequence of the emotion or of the visual presentation of the oysters and their being associated with indigestibility. Nevertheless, since the object of our disgust is immediately represented as being indigestible, we may say in a loose sense that we perceive the indigestibility of oysters. 25

Similar explanations apply to the case of fear. The difference between fear and disgust may be that we do not need to rely on a general belief to construe the object of fear as dangerous. After all, to perceive that a barking dog is dangerous, we do not need to experience any emotion; this is simply something that is perceived independently of any emotion, as we have already suggested. Alston $(1967,485)$ made this point a long time ago: 'two people can see a snake as equally dangerous . . . and yet one is gripped with fear while the other is calm.' Thus, although we have a unified experience of fear toward a dangerous barking dog, we claim that the best explanation of this experience is that it is in 
fact the co-occurrence of two independent psychological mental states: on the one hand a perception - as ordinarily understood - of a barking dog as dangerous, and on the other hand the fear of this same barking dog.

To sum up, evaluative enrichment of the contents of our emotions can come from concurrent perceptual states, including those that constitute the emotions' so-called 'cognitive bases'26, or from more or less robust associations with general beliefs acquired through various habits and past experiences. The most important point that we want to emphasize here is that such enrichment processes are compatible with the spontaneity of our evaluative judgments. That is, the subject is not conscious of inferring evaluative judgments on the basis of her emotions. The relevant heuristics are triggered by emotional and perceptual stimuli in such a way that the emotion itself can seem to have an evaluative content independently of the actual formation of the corresponding judgment. In other words, we suggest that some emotions (wrongly) seem to be perceptions of values because we are immediately aware that they represent value properties and because we take this immediate awareness for a presentation. As we already have shown, such a conflation is paradigmatically instantiated by the Stop sign. We are just seeing the Stop sign, but because the link between Stop signs and what we should do as cautious drivers is deeply entrenched in our knowledge and behavior, we are immediately aware that we should stop our car. Therefore, it is no surprise that the value associated with an emotion type comes immediately to mind as soon as we have an emotion of that type.

We suggest therefore that the value attributed to the object of an emotion is never part of its presented content. Even if we are immediately aware of an evaluative content when we have an emotion, it is either because we perceive the value independently of our emotion as in the case of danger, or because there is an acquired heuristic or cognitive habit that enriches the non-evaluative content of the emotion. In this last case, the acquired heuristic or cognitive habit is the result of our past experiences from which we have learned that a type of emotion represents a certain response-independent value.

\section{Conclusion}

In this paper, we have explored the prospects of what we have called 'the direct access thesis', namely the thesis that emotions are perceptions of values in the sense that they present an evaluative content, and therefore values. Our main conclusion is that the prospects for a defence of the direct access thesis are dim. There are strong reasons to 
believe that emotions are not cases of openness to values, whether the latter are construed as response-dependent or response-independent properties. Although this conclusion is compatible with the existence of interesting analogies between emotions and perceptions, it certainly prevents any epistemologically relevant assimilation of the former to the latter. Beyond this negative conclusion, we have positively emphasized various ways in which the apparent content of emotions can be enriched in such a way that it seems to be evaluative. Explicit and implicit beliefs, cognitive habits, past experience and associations can add evaluative materials to the value-free contents of our emotional experiences. Different types of enrichment process are appropriate for different emotions, and only a detailed account of each emotion and its appropriateness will allow us to definitively resist the initial attractions of the direct access thesis.

\section{Acknowledgements}

We would like to thank two anonymous referees for their most helpful comments. We have also benefited from valuable feedback from audiences in Montreal (CREUM), The Hague and Rennes, as well as very useful remarks from Kevin Mulligan and Fabrice Teroni on a previous version of the paper. Above all, we would like to thank Christine Tappolet for her generosity in stimulating our reflection on these topics.

\section{Notes}

13. See, e.g., McDowell (1998, 143), D’Arms and Jacobson (2000b, 726-727; 2005, 189), Tappolet $(2000,52)$.

14. Both expressions have several occurrences in D'Arms and Jacobson (2000a, 66-67). Interestingly, these expressions have disappeared in their 2005 although they explain at great length why emotions are perceptions of values. In so far as they insist in the latter paper (see its

section 4) on the distinction between the normal conditions that allow us to attribute a dispositional property and the conditions in which an object merits an experience of fear, one may conjecture that they have sensed that what enables the ascription of an evaluative property

is in fact not presented in the experience itself but in the wider conditions in which the emotion is experienced. As we will see later, to adopt this view is to renounce the direct access thesis. 
See especially our Section 3.3.

15. We are here grateful to a reviewer for raising this possibility.

16. We take this suggestion from Goldie $(2004,97)$ although he himself rejects it.

17. The Fitting Attitude Analysis of value goes back to Brentano (1969) but has recently undergone a strong revival, thanks especially to Scanlon (1999). Defenders of the Fitting Attitude Analysis of value diverge on the normative concept that must appear in the analysis. Although D'Arms and Jacobson and Tappolet use 'appropriate', others prefer for example 'required'. Beyond this first debate, most of these authors consider that the relevant concept must be normative whereas Tappolet (2011) argues in favor of a non-normative reading of 'appropriate'. These debates have little bearing on what is at stake here. The objection that we raise in the next paragraph would apply mutatis mutandis for any such analysis of values. 18. It is worth noting that more recently, Deonna and Teroni (2012) have moved away from the direct access thesis.

19. Or indeed color, if it is conceived as a response-independent property; see Section 4.1 below.

20. Indeed, one might argue that the Gestalt imposed on the object of our emotions is not part of the content of emotion but results from further judgments about this content.

21. In fact, we do not know whether she really endorses this view for she insists in other places that the bodily experience must contribute to the evaluative content of emotions. By the way, it is quite telling that she acknowledges that she is unsure whether the value presented in fear is 'fearsome or danger' $(2007,374)$.

22. This is the main tenet of the so-called appraisal theory of emotions which dominates the psychological research on emotion (Lazarus 1991; Frijda 1986; Scherer et al. 2001).

23. Neither do we want to commit ourselves to the appraisal theory of emotions. As we hope to have made evident, we are only considering to what extent the acceptance of the appraisal theory may help the friend of the direct access thesis.

24. This might be Tappolet's current view (personal communication).

25. We therefore agree with Brady (2010, especially 126-127) that the attribution of response-independent values to the objects of our emotions depends on a capacity to recognize these values that is independent of our emotions.

26. The cognitive state, whether it is a perception, an imagination, a thought or a belief, that is responsible for triggering an emotion is often called its cognitive basis; see Teroni (2007).

\section{References}


Alston, W. P. 1967. "Emotion and Feeling.” In Encyclopedia of Philosophy, edited by P. Edwards. New York: Macmillan.

Aydede, M. 2005. “The Main Difficulty with Pain.” In Pain, New Essays on Its Nature and the Methodology of Its Study, edited by M. Aydede. Cambridge, MA: MIT Press.

Brady, M. S. 2010. "Virtue, Emotion, and Attention.” Metaphilosophy 41: 115-131.

Brentano, F. 1969. The Origin of our Knowledge of Right and Wrong, edited by Oskar Kraus and Roderick Chisholm, translated by Roderick Chisholm and Elizabeth Schneewind. London: Routledge \& Kegan Paul.

D’Arms, J., and D. Jacobson. 2000a. “The Moralistic Fallacy: On the 'Appropriateness' of Emotions.” Philosophy and Phenomenological Research 61 (1): 65-90.

D’Arms, J., and D. Jacobson. 2000b. “Sentiment and Value.” Ethics 110: 722-748.

D’Arms, J., and D. Jacobson. 2005. “Sensibility Theory and Projetivism.” In Oxford Handbook of Ethical Theory, edited by D. Copp. Oxford: Oxford University Press.

Deonna, J. A. 2006. "Emotion, Perception and Perspective.” Dialectica 60 (1): 29-46.

Deonna, J. A., and F. Teroni. 2008. Qu'est-ce qu'une e'motion? Paris: Vrin.

Deonna, J. A., and F. Teroni. 2012. The Emotions: A Philosophical Introduction. London: Routledge.

De Sousa, R. 2002. "Emotional Truth.” Proceedings of the Aristotelian Society 76: 247-263.

Döring, S. A. 2007. "Seeing What to Do: Affective Perception and Rational Motivation." Dialectica 61 (3): 363-394.

Frijda, N. H. 1986. The Emotions. Paris: Cambridge University Press and Editions de la maison des sciences de l'homme.

Goldie, P. 2000. The Emotions: A Philosophical Exploration. Oxford: Oxford University Press.

Goldie, P. 2004. “Emotion, Feeling, and Knowledge.” In Thinking about Feeling, edited by R. C. Solomon. Oxford: Oxford University Press.

Johnston, M. 2001. "The Authority of Affect.” Philosophy and Phenomenological Research 53:139-174.

Lazarus, R. S. 1991. Emotion and Adaptation. New York: Oxford University Press.

Meinong, A. 1972. On Emotional Presentation. Evanston: Northwestern University Press.

McDowell, J. 1996. Mind and world. Cambridge, MA: Harvard University Press.

McDowell, J. 1985. "Values and Secondary Qualities.” Reprinted in J. McDowell 1998. In Mind, Value and Reality. Cambridge, MA: Harvard University Press. 
McDowell, J. 1998. Mind, Value, and Reality. Cambridge, MA: Harvard University Press. Mulligan, K. 1998. "From Appropriate Emotions to Values." The Monist 81 (1): 161-188. Peacocke, Ch. 1992. A Study of Concepts. Cambridge, MA: MIT Press.

Pettit, P. 1991. "Realism and Response-Dependence.” Mind 100 (4): 587-626.

Prinz, J. 2004. Gut Reactions: A Perceptual Theory of Emotion. New York: Oxford University Press.

Prinz, J. 2006a. “Is Emotion a Form of Perception?” Canadian Journal of Philosophy, Supplementary Volume 32: 137-160.

Prinz, J. 2006b. "Beyond Appearances: The Content of Sensation and Perception." In Perceptual Experience, edited by T. S. Gendler and J. Hawthorne. Oxford: Clarendon Press. Prinz, J. 2007. The Emotional Construction of Morals. Oxford: Oxford University Press. Roberts, R. C. 2003. Emotions, An Essay in Aid of Moral Psychology. Cambridge, MA: Cambridge University Press.

Salmela, M. 2011. "Can Emotion be Modelled on Perception.” Dialectica 65 (1): 1-29. Scanlon, T. M. 1998. What We Owe to Each Other. Cambridge, MA: Belknap Press. Scherer, K. R., A. Schorr, and T. Johnstone, eds. 2001. Appraisal Processes in Emotion: Theory, Methods, Research. Oxford: Oxford University Press.

Solomon, R. C. 1976. The Passions. New York: Doubleday.

Tappolet, Ch. 2000. Emotions et Valeurs. Paris: Presses Universitaires de France.

Tappolet, Ch. 2011. "Values and Emotions: Neo-Sentimentalist's Prospect." In Moral Emotions, edited by C. Bagnoli. Oxford: Oxford University Press.

Teroni, F. 2007. "Emotions and Formal Objects.” Dialectica 61 (3): 395-415.

Tye, M. 2008. "The Experience of Emotion: an Intentionalist Theory.” Revue internationale de philosophie 243: 25-50.

Wiggins, D. 1987. “A Sensible Subjectivism.” In Needs, Values, Truth. Oxford: Clarendon Press.

Whiting, D. 2012. “Are Emotions Perceptual Experiences of value?” Ratio 25 (1): 93-107. 